\title{
THE CHALLENGE OF BETEL NUT CONSUMPTION TO ECONOMIC DEVELOPMENT: A CASE OF HONIARA, SOLOMON ISLANDS
}

\author{
Stephen Pratt*
}

The chewing of betel nut is prevalent throughout the Asia-Pacific region, especially in the Pacific subregion. Consumed for its stimulant properties, there is concern over this habit's association with negative health consequences. The present study examines the case of Honiara in Solomon Islands where the prevalence of betel nut consumption has increased in recent years, especially among schoolchildren. The potential negative health costs and increasing proportion of household income used to sustain this habit has a negative impact on economic development. Possible solutions are suggested to curb betel nut consumption, but they are fraught with difficulties and barriers to change. A major culture change is needed to stem this rising trend.

JEL Classification: 115, E26, 017.

Key words: Areca, betel nut, economic development, Pacific islands, Solomon Islands, oral health.

\section{INTRODUCTION}

In 1999, as many as 200 million people chewed betel nut (Areca catechu) regularly in the Asia-Pacific region (Chen, Johnson and Taufu, 1999). People chew betel nut because it is a stimulant that produces a mild psychoactive effect. This feeling of "drunkenness" or euphoria is addictive. Betel nut use is widespread, affecting approximately 20 per cent of the world's population (Warnakulasuriya, 2002). The chewing of betel nut is especially prevalent in the Pacific islands. In fact, betel nut

\footnotetext{
* Dr. Stephen Pratt, the Hong Kong Polytechnic University, 17 Science Museum Road, TST East, Kowloon, Hong Kong (Tel: +852 3400 2268; fax: +852 2362 9362; e-mail: Stephen.pratt@polyu.edu.hk). Special thanks to the University of the South Pacific Solomon Island MBA students for their assistance with the data collection.
} 
consumption in Papua New Guinea is more widespread than drinking alcohol, smoking tobacco or consuming caffeine (Chen, Johnson and Taufu, 1999). In Solomon Islands, data from 2005-2006, indicated that the prevalence of betel nut chewing was 62.5 per cent of the population (World Health Organization, 2010). There is anecdotal evidence that this figure has increased.

The "betel nut quid" is actually comprised of three parts: the areca nut (Areca catechu) from the betel palm; the leaf, bean or the bark from the betel vine (Piper bet/e); and the slaked lime (calcium hydroxide) from coral or shells (Norton, 1998). When chewed together, the quid produces a blood-red colour. This red juice stains the teeth and gums and after many years of use, the teeth of the chewer can become black (Norton, 1998). The quid is placed in the mouth. It is then held against the inside of the mouth and the molars and chewed episodically to extract the juice (Winstock, 2002).

Betel nuts are ovoid with a pointed apex usually three to five centimetres long and two to four centimetres wide (World Health Organization, 2004). The preparation of the betel quid differs by location. In Solomon Islands, the fibrous husk of the young nut is ripped off with the teeth and the nut is chewed, while the betel leaf is dipped in the lime, bitten off and chewed in unison with the nut (Norton, 1998). Lime powder is used to enhance the stimulant effect of the betel nut. The saliva and lime powder breaks down the arecoline, the acid-based alkaloid found in the areca nut, to produce the central nervous stimulant (Norton, 1998).

Much research exists on the harmful health effects of betel nut consumption (Zhang and Reichart, 2007), of which most of it has been epidemiological, with less attention directed at the socioeconomic impacts of it (Croucher and Islam, 2002; Williams and others, 2002). The present paper provides an updated examination into betel nut consumption in Honiara, the capital of Solomon Islands, as previous studies are somewhat dated (Wilson and South Pacific Commission, 1983; World Health Organization, 2010). It also discusses the possible negative effects of betel nut consumption in terms of health costs and diversion of income towards betel nut and away from basic necessities and provides a comparison of these with the possible positive impacts in terms of household income from growing, transporting and selling betel nut. Using intercept surveys conducted among 259 adults and 102 schoolchildren based in Honiara, this research seeks to determine the prevalence of betel nut chewing among those two cohorts. It reveals the main motivations for chewing betel nut and the perceived effects that chewers experience. Other data on chewing behaviour, such as frequency and length of chewing and intention to quit are also captured. Among non-consumers, the research captures the main reasons for not partaking in betel nut consumption. Additionally, in-depth interviews were held with medical practitioners in Honiara to understand the frequency and types of 
medical problems specifically associated with betel nut consumption in the capital city. The paper then concludes by critically evaluating a range of recommendations to minimize the negative impacts of betel nut consumption that may hinder economic development in the island State.

\section{HEALTH IMPACTS OF BETEL NUT}

Betel nut consumption affects the body by stimulating the nervous system and dilating blood vessels. The physical effects from chewing betel nut include increased heart rate and sweating. Betel nut consumption also aids digestion and the absorption of food by increasing the muscular activity in the intestines. In developing countries, there is evidence that some people chew betel nut to suppress their appetite. Low-income betel nut chewers may satiate their appetites through betel nut to avoid buying food. The "attraction" of chewing betel nut is that it produces a psycho-stimulating and euphoria-inducing effect for the consumer. The majority of chewers experience those effects within five minutes and the experience lasts for approximately two to three hours (Chu, 1993). Guha (2006) argues that betel leaf has been used to treat various ailments, such as halitosis, boils and abscesses, constipation, headaches, itches, mastitis, conjunctivitis, ringworm and rheumatism. Reported health impacts differ between cultures. Reid (1985) reports that betel nut consumption has allegedly prevented burping after meals, diarrhoea, dysentery and scurvy. In some societies, it is reported to aid menstruation. It can increase the capacity for physical exercise and mental sharpness, lessen fatigability and provide a sense of well-being (Deng and others, 2001; Guha, 2006; Hirsch, 1990; Williams and others, 2002). It is also reported to be an aphrodisiac (Williams and others, 2002). Betel nut has long been used in Chinese medicine, primarily to rid parasites, such as roundworms and tapeworms, in the intestinal tract (Reid, 1985; Zhang and Reichart, 2007). However, because of its addictive nature, chronic daily use often occurs as users attempt to avoid withdrawal symptoms (Gupta and Warnakulasuriya, 2002).

In contrast to the reported positive health impacts, betel nut consumption has been proven to cause oral cancer and cancer of the oesophagus. Other research has shown that betel nut consumption leads to asthma (Taylor and others, 1992) and cancer of the pharynx (Lee and others, 2005). There is evidence that it provides a low level of toxicity in chewers (Deng and others, 2001) and can have adverse effects on newborns of chronic betel nut users (López-Vilchez and others, 2006; Senn and others, 2009). Tests done on betel quid chewers show that they tend to have higher blood pressure than non-users and suffer from hypertension (Heck and others, 2012). The spitting of betel nut juice indiscriminately in public places helps transmit and spread respiratory infections (Williams and others, 2002). 


\section{THE SOCIOECONOMIC IMPACTS OF BETEL NUT}

The consumption of betel nut can have profound sociocultural and economic impacts on an economy. Users start relatively early in life in the Federated States of Micronesia, 12 years was the mean age of initiation and those school-aged children had already reported symptoms of poor oral health (Oakley, Demaine and Warnakulasuriya, 2005). Betel nut usage is also highly associated with the chewing of tobacco (World Health Organization, 2012). This can compound the negative health effects of betel nut consumption. In developing countries, costs associated with betel-nut related illnesses have the potential to drain public funds.

Income spent on betel nut among populations in developing countries can divert funds away from basic necessities. These basic necessities, such as electricity and water, may already be too expensive for some households or in limited supply due to poor infrastructure. Thus, household expenditure on betel nut can contribute to an even poorer standard of living. The World Bank (2014a) notes that Solomon Islands currently has one of the lowest rates of electricity access in the world and some of the highest electricity prices (greater than $\$ 0.80$ per $\mathrm{kWh}$ ). In Honiara, which accounts for about 90 per cent of the country's electricity generation and consumption, only 64 per cent of the households are grid connected. In terms of access to water, in 2011, the World Bank reported that only 79.2 per cent of the Solomon Island population had access to improved sources of water (World Bank, 2014b). Maebuta and Maebuta (2009) found that households in Solomon Island squatter settlements spend an average of 8.4 per cent of their annual income on betel nut. In this same study, 96.6 per cent did not have electricity and 92.3 per cent had no water supply to their home, often because those services were too expensive. School fees were perceived to be too high, and, as a result, squatter households could not afford to send their children to school (Maebuta and Maebuta, 2009).

In Papua New Guinea, Gibson (2000b) found that the average share of total expenditure spent on betel nut was 3.66 per cent for rural households and 2.09 per cent for urban households. Gibson notes that, along with fish, banana, and sweet potato, betel nut is one of the most important locally produced items in the diets of people from Papua New Guineans.

The chewing of betel nut also has cultural implications. The mild psychic and euphoric effect can aid the reconciliation process of negotiation among disagreeing tribes. Betel nut consumption is closely linked with speechmaking, authority and politics in Papua New Guinea (Hirsch, 1990). At times, it has been used for healing, gifts and cementing relationships, and as a welcome offering (Chen, Johnson and Taufu, 1999). It has symbolic significance in many cultures and is consumed when paying homage, recognizing courtships, betrothals and marriages and at funerals and 
ancestral remembrances (Guha, 2006; Malinowski, 1921; Norton, 1998; Reid, 1985; Sharp, 2013; Williams and others, 2002).

The production and sale of betel nut can provide an essential source of income for many households in countries where it is consumed. Often, betel nut sellers, who are outside the formal economy, have few other economic alternatives to generate income. Income from betel nut sales go directly towards school fees, food, medicine and other everyday household requirements. A recent study from Solomon Islands estimated that 43.6 per cent of all households grew betel nut as a cash crop in 2009 (Solomon Islands, 2009). Previous estimates were somewhat lower, with 17 per cent of households in 1986 and 30 per cent of households in 1999 reporting that they grew betel nut as a cash crop. The reasons for this growth may include the increased demand for betel nut consumption and/or the monetization of what was once a largely subsistence activity. Yet, in 2009, in the urban centre of Honiara, only 1.1 per cent of households grew betel nut.

Increasing urbanization may be contributing to the increased demand for betel nut, as betel nut cannot be grown in sufficient quantity in urban areas. Solomon Islands (2009) reports that, while the rural population grew from 1970 to 2009 by an average of 5.2 per cent per annum, the population of Honiara province grew by an annual average of 11.2 per cent. This growth in the urban population may indicate that Solomon Islanders who previously grew their own betel nut on their property in the rural areas may now need to purchase the product while residing in Honiara.

While those in Honiara do not directly benefit from the production of betel nut, many residents generate income as a "middleman" between betel nut farmers and end consumers. Betel nut is widely available, with small sellers being found in many locations, as well as in specified markets (Solomon Islands, 2009). Many roadside makeshift stalls sell betel nut, the fruit leaf and lime along with single cigarettes. A recent report (World Health Organization, 2010) estimates that in Solomon Islands, a betel nut seller could earn up to $\$ 63.49$ per day.

Elsewhere in the Pacific subregion, Gibson (2000a) reported that an estimated 1.23 million people received income from betel nut in Papua New Guinea in 1996. This represented 25.4 per cent of the population at that time. The economic value of this betel nut income was $\$ 7.094$ million, or 9.5 per cent of the total national income from agricultural products.

Previous research has found that betel nut consumption in Solomon Islands is common at all levels of society, with most islanders having chewed betel nut at some time in their life (Wilson and South Pacific Commission, 1983). More than 50 per cent of adults were estimated to have chewed betel nut at least once a week. Both women 
and men were as likely to chew betel, but men had a lower age of initiation and were heavier users. Young children commonly chew the betel nut husk then progress to chewing betel nut. The regular chewing of betel quid was not commonly observed before puberty (Wilson and South Pacific Commission, 1983).

In Bangladesh (Heck and others, 2012) and in Taiwan Province of China (Ko and others, 1992), researchers found a negative relationship between betel nut consumption and education level and employment. With regard to Indonesia, Reid (1985) says that males have switched to tobacco smoking while females have not embraced tobacco smoking to the same extent. Rural communities consume more betel nut than urban communities.

This brief review outlines some of the literature on the health and socioeconomic impacts that betel nut consumption and production can have on an economy. The focus of the review has been on literature in the context of the Pacific subregion.

\section{METHODOLOGY}

The research undertaken in the present study contains three categories of respondents: Solomon Island adults, schoolchildren and health personnel. The research among the Solomon Island adult cohort used a convenience sample in and around Honiara. The two-page survey instrument was derived from the extensive literature review cited above. The survey instrument captured prevalence of betel nut chewing, the main motivations for chewing and the perceived effects that chewers experience. Frequency of consumption and average length of chewing of each betel nut, age of the respondent when first started chewing, and intention to quit are all also asked in the questionnaire. Chewers were also asked how much they spent on the three components of the quid: the betel nut, the leaf and the lime. Among non-chewers, the research captured the main reasons for not partaking in betel nut consumption. Demographic questions included age, gender, level of education, home province and employment status. For the research, SPSS version 20 was used to analyse the data.

A total of 259 surveys among Solomon Island adults were completed in June 2014. The profile of the sample closely matched the population profile. The gender split was 53.4 per cent/46.6 per cent male/female, while the age breakdown was 18.3 per cent: $18-24$ years; 43.3 per cent: $25-34$ years; 19.9 per cent: $35-44$ years; 10.6 per cent: $45-54$ years; 4.8 per cent: $55-64$ years; and 3.0 per cent: 65 years or older. 
The research among Solomon Island schoolchildren was conducted in June 2014. The survey instrument was adapted from Oakley, Demaine and Warnakulasuriya (2005), which was a one-page questionnaire that captured data on prevalence and frequency of betel nut, alcohol and tobacco consumption, as well as on awareness of the harmful effects of betel nut consumption. One hundred and two schoolchildren were interviewed across seven different schools in and around the Honiara area. The selection of schoolchildren came from King George Sixth High School, Bokona Community High School, Saint John Community High School, Saint Nicolas Community High School, Honiara Senior Secondary School, Panatina Community High School and Bishop Epalle High School. There was a relatively even split by gender (53.9 per cent male). The age of the schoolchildren ranged from 13 years to 21 years, with 48 per cent of the sample aged 16 years or younger.

The health personnel survey was conducted among health professionals, including dentists, medical doctors and registered nurses. Twenty health professionals were approached in July 2014 to complete the survey. Ten health professionals agreed to respond to the in-person interview. Six respondents were male. Five respondents were doctors, with the remaining five being nurses. The level of experience of those health professions ranged from 1 year to 23 years, with an average of 13 years in practice. Six respondents practised at the National Referral Hospital, another three practised at Honiara City Council clinics and one was a single private medical centre doctor. These health professionals were asked how many patients they see with medical problems specifically associated with betel nut consumption and how many other patients they see with other medical issues that have symptoms of betel nut consumption. For those patients who specifically seek medical attention as a result of betel nut consumption, the symptoms they experienced were sought. Lastly, these health professionals were asked if they had advised patients to stop chewing betel nut.

The author also tried to obtain detailed information on the costs associated with treating betel nut induced health problems. However, those costs could not be retrieved from the National Pharmacy Division nor the Planning and Finance Division of Ministry of Health.

\section{FINDINGS}

\section{Adults}

This research revealed that 81.0 per cent of the respondents chewed betel nut. This number was significantly higher than the prevalence of betel nut consumption found in earlier studies. While not directly comparable, the World Health Organization 
(2010) estimated the prevalence of betel nut consumption across three districts: Honiara, Western Province and Malaita, at 62.6 per cent in 2006 (67.8 per cent of men and 57.3 per cent of women). Unfortunately, the World Health Organization report did not separate prevalence by province. Unlike Wilson and South Pacific Commission (1983), both women and men were as likely to chew betel. Those from Malaita province were statistically significantly more likely to chew betel nut than Solomon Islanders whose home province is Guadacanal Province (86.4 per cent versus 66.1 per cent).

As found by Heck and others (2012) in Bangladesh and Ko and others (1992) in Taiwan Province of China, there was a negative relationship between betel nut consumption and education level (table 1). In this study, 69.6 per cent of those with tertiary education consumed betel nut compared to 89.7 per cent without tertiary education. In terms of frequency, 73.0 per cent of those who chew partook every day while a further 12.9 per cent chewed at least once a week but not every day and 14 per cent consumed betel nut less than weekly. The large majority (93.9 per cent) of betel nut consumers obtained their supply from a market stall and a further 5.5 per cent grew betel nuts for their own consumption.

\section{Table 1. Prevalence of betel nut consumption (per cent)}

\begin{tabular}{|c|c|c|c|c|c|c|c|c|}
\hline & \multicolumn{3}{|c|}{ Gender } & \multicolumn{3}{|c|}{ Province } & \multicolumn{2}{|c|}{ Education level } \\
\hline & Total & Male & Female & Guadacanal & Malaita & $\begin{array}{c}\text { Other } \\
\text { provinces }\end{array}$ & Tertiary & $\begin{array}{l}\text { Below } \\
\text { tertiary }\end{array}$ \\
\hline Yes & 81.0 & 84.5 & 76.9 & 66.1 & $86.4^{*}$ & 82.6 & 69.6 & $89.7^{\star}$ \\
\hline No & 19.0 & 15.5 & 23.1 & 33.9 & 13.6 & 17.4 & 30.4 & 10.3 \\
\hline
\end{tabular}

Source: Author's calculations.

Note: * indicates 5 per cent significance level from adjacent column.

Consumers chewed an average of 11.4 betel nut quids each day (median $=8$ ). Again, there were statistically significant differences by education level with those with tertiary education chewing an average of 7.2 quids per day while those less educated chewed an average of 13.6 betel nut quids per day. Adult respondents were asked, on average, how long did each betel nut last. Each betel nut lasted an average of 1 hour and 15 minutes (median $=10$ minutes). When asked what age the respondent first chewed betel nut, the average age was 16.2 years with a median age of 15 years. Unlike previous studies, there was no statistically significant difference in the age of initiation between males and females. However, among those interviewed, there was evidence to suggest that the age of initiation was getting younger. The 18 to 34 year olds commenced chewing betel nut at the average age of 14.5 years, those aged 
between 35 and 44 years commenced at the average age of 18.5 years while those aged 45 years or older stated that they started chewing betel nut at 20.2 years of age.

Betel nut consumers surveyed in this study were spending a significant proportion of their income on betel nut. The average price of a betel nut was 2.23 Solomon Islands dollar (SI\$) (US\$0.29), the average price of the leaf is SI\$1.02 and the price of lime was on average SI $\$ 0.83$ (meaning that the average price of a betel nut quid in Solomon Islands was SI\$4.09). When multiplied by the number of betel nut quids consumed per day and the amount of days per week betel nut was consumed, the average weekly amount spent on betel nut was SI\$338.44 (median = SI\$175.00). The median yearly expenditure per betel nut consumer was SI\$9,100. This was similar to Palau, where a regular betel nut chewer spent $\$ 32.55$ a week on betel nut, which equated to $\$ 1,692.60$ per year (World Health Organization, 2012). The median betel nut expenditure represented 8.5 per cent of the median annual household income of a Solomon Islander residing in Honiara (Solomon Islands Statistics Office, 2006). This estimate is not insignificant given the negative health and social costs associated with its consumption. Furthermore, in terms of nutrition, only negligible amounts of protein and energy are in the ingredients contained within the betel nut supply, and betel nut and the associated betel quid ingredients may be bought in preference to nutritious food (Weegels, Heywood and Jenkins, 1984).

Table 2 shows the results of the query in the survey on the reasons for chewing betel nut. Among the reasons cited were the euphoric effect (69.3 per cent), followed by mouth freshening (63.8 per cent). Almost half of all chewers (42.9 per cent) believed it relieved boredom, while a host of other reasons, including more energy, combats hunger, aids digestion and increases mental insight, were cited by about a third of all chewers. In terms of differences by segment, females were more likely than males to state that chewing betel nut aids digestion $(24.0$ per cent males; 38.9 per cent females). Young adults (18-34 years) were more likely to chew because they believe it made their lips look attractive (40.3 per cent: $18-34$ years; 15.3 per cent: $45+$ years). Young adults were also more likely to chew for something to do than those in the older age brackets (48.9 per cent: $18-34$ years; 17.0 per cent: $45+$ years).

Betel nut consumers were asked the strength of their intention to quit chewing betel nut. Over a third of chewers (35.9 per cent) had no intention to quit betel nut consumption, while almost half (48.7 per cent) had a moderate intention to quit chewing and only 15.3 per cent of chewers had a strong intention to quit chewing betel nut. Interestingly, females were more likely to have no intention to quit than males (no intention to quit: 29.2 per cent males/44.8 per cent females).

Of those who did not chew betel nut (19 per cent of the total sample), the main reasons cited include being bad for health (63.3 per cent), against religious beliefs 
Table 2. Motivations for chewing betel nut

\begin{tabular}{lc}
\hline \multicolumn{1}{c}{ Reason } & Percentage \\
\hline Makes you feel good & 69.3 \\
Makes your breath smell nice & 63.8 \\
Is good to pass the time & 42.9 \\
Makes me less tired & 35.3 \\
Makes me less hungry & 33.8 \\
Makes your lips look attractive & 32.8 \\
Helps you to digest your food & 30.7 \\
Increases my mental sharpness & 27.8 \\
Increase my ability for physical exercise & 22.5 \\
Increases my sex drive & 3.4 \\
Other reasons & 14.1 \\
\hline
\end{tabular}

Source: Author's calculations.

(59.5 per cent), did not like the taste (44.7 per cent) and do not like the red stains on their mouth (15.1 per cent). Those who do not chew betel nut for religious reasons tended to be Seventh Day Adventists (Solomon Islands, 2009).

\section{Schoolchildren}

Among the schoolchildren surveyed, the prevalence of betel nut consumption was 68.6 per cent as compared to 3.9 per cent of schoolchildren who consumed alcohol and 19.6 per cent who smoke tobacco cigarettes. Schoolchildren who consumed betel nut chewed an average of 2.11 quids per day (median 1.0) and schoolchildren who used tobacco smoked an average of 4.1 cigarettes per day (median 3.0). There was no statistically significant difference in betel nut or tobacco use by gender, at least at the 95 per cent level of confidence. Over a third (38.6 per cent) of those who chewed betel nut swallowed the betel nut juice. As found by Wilson and South Pacific Commission (1983), the use of lime was common but not universal. The large majority (78.6 per cent) of those who chewed betel nut consumed the nut, the leaf and the lime together. 14.3 per cent of school children chewed the betel nut by itself, while only 7.1 per cent consumed the betel nut and leaf together, that is, without the lime.

The large majority of schoolchildren surveyed (89.2 per cent), including almost all of the betel nut consumers (97.1 per cent), were aware that betel nut consumption causes mouth cancer. In fact, there was greater awareness of that fact among betel 
nut consumers than non-chewers (97.1 per cent versus 71.9 per cent, $p<0.05$ ). Among this cohort, that behaviour may be explained by hyperbolic discounting, that is, the tendency for people to increasingly choose a smaller-sooner reward (the buzz from chewing betel nut) over a larger-later reward (good health later in life) (Heath, 2009 , p. 221). Schoolchildren may perceive the chances of a betel-nut-induced ailment as so small and the negative consequences of betel nut consumption far into the future, so that when offered the opportunity to chew betel nut, the attraction of the immediate euphoria takes precedence.

There was a moderate positive correlation between tobacco consumption and betel nut consumption among schoolchildren $(r=0.281, p=0.004)$. Of those who smoked, 95.0 per cent also chewed betel nut, while the prevalence of betel nut consumption among non-smokers was 62.2 per cent, a statistically significant difference at the 95 per cent level of confidence. Similarly, betel nut chewers were more likely to smoke - the prevalence of tobacco use among betel nut chewers was 27.1 per cent compared to 3.1 per cent among non-chewers. Smokers were also more likely to consume alcohol than non-smokers (15.0 per cent versus 1.2 per cent respectively).

\section{Health professionals}

Seven out of the ten health professionals interviewed reported that they had seen patients with medical problems specifically associated with betel nut consumption in the previous month. That included the health professionals that worked at the dental clinic. Three of those seven health professionals had also seen patients who had other medical issues, but also had symptoms associated with betel nut consumption. That potentially creates a situation of a double disease burden in which there may be complications from betel nut chewing which are combined with other diseases.

Of those patients who specifically sought medical attention as a result of betel nut consumption, the most common health issues patients experienced (in order of mentions) were oral cancer, cancer of the oesophagus, cancer of the pharynx, high blood pressure and diarrhoea. The health professionals interviewed reported advising patients at some point to stop chewing betel nut for various reasons. Health professionals had asked patients with any abnormal features to the mouth, oral mucosa, tongue, gum or teeth to stop chewing betel nut. Chairside education regarding oral hygiene and the importance of preventative measures was usually provided to patients. 


\section{DISCUSSION AND CONCLUSIONS}

This sample of Honiara residents indicated that betel nut consumption is on the increase with the prevalence among adults being 81.0 per cent and the prevalence among school-aged children being 68.6 per cent. The long-term health problems associated with continued betel nut consumption include oral cancer, tooth discoloration and dental caries and periodontal disease. Increased usage will continue to put pressure on the health system of Solomon Islands, creating an additional burden for medical practitioners and the Government. Health professionals in Solomon Islands reported that Honiara residents were seeking medical help for betel nut-induced health issues. Furthermore, those seeking health care for non-betel nut-induced problems also exhibited symptoms of excessive betel nut consumption, potentially leading to a double disease burden. Betel nut consumption and tobacco use were positively correlated and health issues will be exacerbated with this co-consumption. In the markets and at roadside stalls in and around Honiara, the supply of betel nut and tobacco cigarettes makes consumption relatively easy for those who choose to consume.

These increasing health costs could divert government funds away from other productive uses, such as infrastructure development and educational resources. The health effects could diminish the ability of the working population to offer their labour. Against these negatives, the informal economy of betel nuts generates significant economic benefits in developing countries. Economic benefits associated with betel nut production are mainly enjoyed in the rural areas. However, the on-selling of betel nut in the urban centre of Honiara, provides an important source of income for the population. Hence, this informal economy could help alleviate poverty in developing countries, as seen in the Honiara case.

The sociocultural environments of Pacific island countries, including Solomon Islands, have a long-established habit of betel nut use, which is integral to community life. It is a socially approved habit that is incorporated into both ceremonial situations and routine aspects of daily life. As described by Marshall (1987, p. 21) "betel is used in informal interpersonal exchanges, in formal presentations, in ceremonials and rituals, in decorations and ornamentation, in trade and commerce, in magic and sorcery, and in medicinal preparations". Given its social importance, curbing consumption will be difficult.

Nevertheless, there have been several policies and recommendations proposed in different countries to diminish or eliminate betel nut's negative influence on economic development. The World Health Organization (2012) has suggested measures that need to be taken to discourage the use of betel nut. WHO suggests that a well-designed communication programme would inform a variety of different 
audiences about the hazards of betel nut and tobacco use and interventions. However, this research has shown that school-aged betel nut consumers are very aware of the negative health effects of betel nut consumption. For schoolchildren, the short-term euphoria of consuming betel nut or the social activity of chewing with friends outweighs the distant, long-term issues of health problems. Being lectured by politicians and teachers may not necessarily be effective. Nevertheless, there may be more that health officials and policymakers could do to influence betel nut consumption. This may be accomplished through the use of sporting or music role models to support education and information campaigns that target youth and children.

Regulation and legislation has been used as a mechanism to stem betel nut consumption (World Health Organization, 2004). There are policies that ban spitting in public places, most notably in health-care facilities and schools, although the enforcement of the ban is rarely, if ever, enforced. As with tobacco consumption, in many developed countries, policymakers could consider a ban on the sale and consumption of betel nut to people under the age of 16 years. The key to any legislation of that kind would be effective enforcement - it is one thing to have a law in place and quite another thing to enforce it. Citizens could be encouraged to monitor and report violations of bans on sales to minors. Diligence would be needed to stop the consumption of betel nut among minors by seeking to ban the sale of betel nut by those selling the quids at market stalls. In Solomon Islands, this would be very problematic given the ubiquity of betel nut for sale and the very informal nature of the production and consumption of betel nut, not to mention the resources needed to adequately monitor this law given the already-stretched law enforcement organizations. Moreover, the policy of banning sales to children may also fail due to the strong "gift" economy in the Pacific subregion (Carrier, 1992) so that adults may purchase the quids and give them to children.

Sharp (2013) highlights the recent case in Papua New Guinea, whereby the newly elected governor of Port Moresby enacted a betel nut ban. The National Capital District Betelnut Control Law 2013 prohibits the sale, consumption and spitting of betel nut in public places within the capital. The Law goes further by banning transportation of more than two kilograms of betel nut into the capital without a permit. This amount is economically viable for smaller sellers, but would exclude commercial transactions by larger traders and market vendors. Selling then, is restricted to designated markets within the city limits, enabling government officials can monitor betel nut sales (Sharp, 2013). This type of legislation may also be an option for Solomon Islands. 
Yet, enforcement of the betel nut ban in Port Moresby has not been without problems. Sharp (2013) reports that in police checks, patrol officers responsible for enforcing the ban have often physically intimidated and attacked vendors and stolen produce. The penalties of a 300 Papua New Guinea kina (\$11) on-the-spot fine, or two-hour community service for first-time offenders and prosecution for repeat offenders may be open to corruption.

In the Marshall Islands, the legislature passed a law in 2010 banning the importation of betel nut and making it a crime to import, distribute or sell betel nut, backed by a fine of up to $\$ 100$ and 30 days in jail (World Health Organization, 2012). This is unlikely to be an option for Solomon Islands, given that betel nut is grown locally and not imported.

Another major obstacle to restricting demand is the availability of supply, not only owing to its prevalence and the informal nature of the betel nut economy, but also due to the fact that betel nut provides an essential source of income for many households. Often, betel nut sellers, who are outside the formal economy, have few other economic alternatives to generate income. Income from betel nut sales go towards school fees and food, medicine and other household expenses. By banning betel nut consumption, household incomes may decline, contributing to increased poverty, as the ability to afford household necessities also decreases.

Policy initiatives to curb demand, such as through regulation and legislation, including the banning of its sale, also present its own sets of problems. A more appropriate platform for action might be public awareness, education, communication and advocacy (World Health Organization, 2012). This may include strengthening communication and advocacy activities by using role models to convey the important messages of the dangers of betel nut, particularly the link to cancer. Policymakers could also fund education and information campaigns that educate the public about the early signs of betel-nut related health conditions and the importance of oral health exams for early detection. Lastly, policymakers could encourage residents to monitor and report violations of bans on sales to schoolchildren. The implementation of those policies will not be an easy task.

This research has several limitations. First, the sampling method used was a convenience sample among Honiara residents and Honiara-based schoolchildren. As such, the findings are not generalizable to the Solomon Island population. Future research could implement simple random sampling or systematic sampling, perhaps by including a series of questions about betel nut consumption and production in an appendix to a census so that the results could be extrapolated to both rural and urban populations. Additionally, health costs of different treatments were not available for Solomon Islands. Even if data on health care costs were available, it may be 
difficult to separate out the costs attributed to betel nut use compared to other sources. Having such data would enable analyses such as cost-benefit analysis to be undertaken, which might shed light on the contribution of betel nut to economic development in Solomon Islands. 


\section{REFERENCES}

Carrier, James G. (1992). The gift of theory and practice in Melanesia: a note on the centrality of gift exchange. Ethnology, vol. 31, No. 2, pp. 185-193.

Chen, Paul C.Y., Felix Y.A. Johnson, and Tukutau Taufu (1999). Societal and health aspects of psychoactive drug abuse in Papua New Guinea. Pacific Health Dialog, vol. 6, No. 1, pp. 93-100.

Chu, N.S. (1993). Cardiovascular responses to betel chewing. Journal of the Formosan Medical Association, vol. 92, No. 9, pp. 835-837.

Croucher, R., and S. Islam (2002). Socio-economic aspects of areca nut use. Addiction Biology, vol. 7 , No. 1, pp. 139-146.

Deng, Jou-Fang, and others (2001). Acute toxicities of betel nut: rare but probably overlooked events. Clinical Toxicology, vol. 39, No. 4, pp. 355-360.

Gibson, John (2000a). The economic and nutritional importance of household food production in PNG. In Food Security for Papua New Guinea: Proceedings of the Papua New Guinea Food and Nutrition 2000 Conference, 26-30 June 2000, R.M. Bourke, M.G. Allen and J.G. Salisbury, eds. Lae, PNG: PNG University of Technology.

(2000b). Food demand in the rural and urban sectors of PNG. In Food Security for Papua New Guinea: Proceedings of the Papua New Guinea Food and Nutrition 2000 Conference, 26-30 June 2000, R.M. Bourke, M.G. Allen and J. G. Salisbury, eds. Lae, PNG: PNG University of Technology.

Guha, P. (2006). Betel leaf: the neglected green gold of India. Journal of Human Ecology, vol. 19, No. 2, pp. 87-93.

Gupta, P.C., and S. Warnakulasuriya (2002). Global epidemiology of areca nut usage. Addiction Biology, vol. 7, No. 1, pp. 77-83.

Heath, J. (2009). Economics without Illusions: Debunking the Myths of Modern Capitalism. New York: Broadway Books.

Heck, Julia A., and others (2012). Betel quid chewing in rural Bangladesh: prevalence, predictors and relationship to blood pressure. International Journal of Epidemiology, vol. 41, No. 2, pp. 462-471.

Hirsch, Eric (1990). From bones to betelnuts: processes of ritual transformation and the development of 'National Culture' in Papua New Guinea. Man, New Series, vol. 25, No. 1, pp. 18-34.

Ko, Ying-Chin, and others (1992). Prevalence of betel quid chewing habit in Taiwan and related socioeconomic factors. Journal of Oral Pathology \& Medicine, vol. 21, No. 6, pp. 261-264.

Lee, Ka-Wo, and others (2005). Different impact from betel quid, alcohol and cigarette: risk factors for pharyngeal and laryngeal cancer. International Journal of Cancer, vol. 117, No. 5, pp. 831-836.

López-Vilchez, Marai Angeles, and others (2006). Areca-nut abuse and neonatal withdrawal syndrome. Pediatrics, vol. 117, No. 1, pp. 129-131.

Maebuta, Jack, and Helen Esther Maebuta (2009). Household livelihoods in Solomon Islands squatter settlements and its implications for education and development in post-conflict context. Paper presented at the Australian Association for Research in Education International Education Research Conference. Canberra, Australia, 29 November - 3 December. Available from www.aare.edu.au/data/publications/2009/mae091005.pdf. Accessed 5 May 2014. 
Malinowski, B. (1921). The primative economics of the Trobriand Islanders. The Economic Journal, vol. 31, No. 121, pp. 1-16.

Marshall, Mac (1987). An overview of drugs in Oceania. In Drugs in Western Pacific Societies: Relations of Substance, L. Lindstrom, ed. Lanham, Maryland, USA: University Press of America.

Norton, Scot A. (1998). Betel: consumption and consequences. Journal of the American Academy of Dermatology, vol. 38, No. 1, pp. 81-88.

Oakley, Eric, L. Demaine, and S. Warnakulasuriya (2005). Areca (betel) nut chewing habit among high-school children in the Commonwealth of the Northern Mariana Islands (Micronesia). Bulletin of the World Health Organization, vol. 83, No. 9, pp. 656-660.

Reid, Anthony (1985). From betel-chewing to tobacco-smoking in Indonesia. The Journal of Asian Studies, vol. 44, No. 3, pp. 529-547.

Senn, M., and others (2009). Betel nut chewing during pregnancy, Madang province, Papua New Guinea. Drug and Alcohol Dependence, vol. 105, No. 1, pp. 126-131.

Sharp, Timothy L.M. (2013). Fear and loathing in Port Moresby: chewing over the betel nut ban. In Brief, vol. 2013/10. Available from http://ips.cap.anu.edu.au/sites/default/files/ SSGM\%20IB\%202013_10_Sharp.pdf. Accessed 5 May 2014.

Solomon Islands (2009). 2009 Population \& Housing Census: Report on Economic Activity and Labour Force. Available from www.spc.int/prism/solomons/index.php/sinsodocuments?view=download\&fileld=61. Accessed 8 September 2014.

Solomon Islands Statistics Office, Department of Finance and Treasury (2006). Household Income and Expenditure Survey Provincial Report 2005/6. Available from www.spc.int/prism/ solomons/index.php/sinso-documents?view=download\&fileld=12. Accessed 12 August 2014.

Taylor, R.F.H., and others (1992). Betel-nut chewing and asthma. Lancet, vol. 339, No. 8802, pp. 1134-1136.

Warnakulasuriya, S. (2002). Areca nut use following migration and its consequences. Addiction Biology, vol. 7, No. 1, pp. 127-132.

Weegels, P., P. Heywood, and C. Jenkins (1984). Consumption of betel nut and its possible contribution to protein and energy intakes. Papua New Guinea Medical Journal, vol. 27, No. 1, pp. 37-39.

Williams, S., and others (2002). Sociocultural aspects of areca nut use. Addiction Biology, vol. 7, No. 1, pp. 147-154.

Wilson, Andrew, and South Pacific Commission (1983). Solomon Islands oral cancer study: a case-control study of the relationship of oral cancer to betel nut use and a review of patterns of consumption of betel nut, tobacco, and alcohol in Solomon Islands. Noumea, New Caledonia: South Pacific Commission.

Winstock, A. (2002). Areca nut-abuse liability, dependence and public health. Addiction Biology, vol. 7 , No. 1, pp. 133-138.

World Bank (2014a). Solomon Islands gets US\$13 million boost to improve efficiency and reliability of electricity services in Honiara, 22 March. Available from www.worldbank.org/en/news/ press-release/2014/03/21/solomon-islands-gets-13-million-improve-efficiency-reliabilityelectricity-services-honiara. Accessed 24 February 2015. 
(2014b). World Bank Indicators - Solomon Islands. Available from http://data.worldbank. org/country/solomon-islands. Accessed 21 January 2014.

World Health Organization (2004). Betel-quid and areca-nut chewing and some areca-nut-derived Nitrosamines. IARC Monographs on the Evaluation of Carcinogenic Risks to Humans. Available from http://monographs.iarc.fr/ENG/Monographs/vol85/mono85.pdf. Accessed 7 July 2014.

(2010). Solomon Islands NCD Risk Factors Steps Report. Available from www.who.int/chp/ steps/2006_Solomon_Islands_STEPS_Report.pdf. Accessed 7 July 2014.

(2012). Review of areca (betel) nut and tobacco use in the Pacific: a technical report. Available from www.wpro.who.int/tobacco/documents/betelnut.pdf. Accessed 7 July 2014.

Zhang, Xiaolin, and Peter A. Reichart (2007). A review of betel quid chewing, oral cancer and precancer in Mainland China. Oral Oncology, vol. 43, No. 5, pp. 424-430. 